\title{
A TEORIA DO SIGNIFICADO DE JAKOB VON UEXKÜLL COMO UM CASO DE TRADUÇÃO RADICAL*
}

\author{
Arthur Araújo** \\ aart037@gmail.com
}

Elaine Cristina Borges de Souza*** criselaineb@gmail.com

RESUMO No segundo capitulo de "Word and Object", Quine procura mostrar o quanto da linguagem pode ser esclarecida em termos estimulantes, bem como a limitação da tradução a partir de diferentes esquemas conceituais. $O$ autor apresenta a tese de indeterminação da tradução por meio de uma situação de tradução radical. O objetivo deste artigo é apresentar de que modo Quine desenvolve a tradução radical e destacar os conceitos de informações colaterais, significado estimulativo e esquema conceitual. Em seguida, procuraremos mostrar que a teoria do significado de Jakob Von Uexküll é um caso exemplar da tese de indeterminação da tradução: os processos de significação entre diferentes organismos vivos correspondem a um processo de tradução radical que se depara com dificuldades semelhantes àquelas que levam à indeterminação da tradução segundo Quine.

Palavras-chave Uexküll, Quine, Significado, Tradução.

* $\quad$ Artigo submetido em 14/07/2017. Aceito em 17/09/2017.

** UFES - Universidade Federal do Espírito Santo, Vitória, ES, Brasil. Departamento de Filosofia/Programa de Pós-Graduação em Filosofia da Universidade Federal do Espírito Santo (Ufes).

*** UFES - Universidade Federal do Espírito Santo, Vitória, ES, Brasil. 
ABSTRACT In the second chapter of "Word and Object", Quine seeks to show how much of language can be elucidated in stimulatory terms as well as the limitation of translating from different conceptual schemas. He introduces the thesis of indeterminacy of translation by means of a radical translation situation. This paper aims to present the way in which Quine develops the radical translation and to point out the concepts of collateral information, stimulus meaning and conceptual schema. Following that, we will seek to show that Jakob von Uexküll's theory of meaning is an exemplary case of the thesis of indeterminacy of translation: the processes of meaning by different living organisms correspond to a radical translation process that faces the difficulties similar to those that lead to the indeterminacy of the translation, according to Quine.

Keywords Uexküll, Quine, Meaning, Translation.

\section{Introdução}

Não se pode negar uma significativa mudança de perspectiva na filosofia analítica entre 1950 e 1970. Uma mudança da qual não seria extravagante afirmar ser uma segunda virada linguística na filosofia contemporânea. Assim como Austin, Sellars e o Wittgenstein tardio, que rompem com a ortodoxia do positivismo lógico segundo a tese de verificação dos conteúdos condicionais dos enunciados (se verdadeiros ou falsos), Willard van Orman Quine (19082000) vai além e mostra uma perspectiva que não traça uma distinção rígida entre filosofia e ciência empírica: o uso de conceitos e resultados tirados das ciências empíricas estaria em continuidade com o vocabulário filosófico.

No Capítulo II de "Word and Object" (1960), Quine formula a tese da indeterminação como alternativa à semântica mentalista: cada expressão de uma linguagem corresponde a um objeto extralinguístico que é seu significado. Mas, se não existem entidades que são os 'significados', em que consiste significar alguma coisa? É aqui que Quine introduz a ideia de tradução: explicar as condições em que uma expressão seria uma tradução correta de uma outra expressão em uma língua diferente. A 'tradução' radical é uma ferramenta de tradução de uma língua desconhecida cujo resultado induz a tese da indeterminação do significado. Segundo Quine, tal indeterminação representa a própria limitação das tentativas de tradução. E o desafio da proposta de tradução radical é que a língua a ser traduzida seja completamente desconhecida (Quine, 1960, p. 27).

Em 1934, o biólogo estoniano Jakob Von Uexküll (1864-1944) apresenta uma teoria do significado como segunda parte da teoria de Umwelt: "[...] 
tudo aquilo que um sujeito assinala passa a ser seu mundo-de-percepção, e o que ele realiza, seu mundo-de-ação. Mundo-de-percepção e mundo-de-ação constituem uma unidade íntegra - o mundo-próprio [Umwelt] do sujeito" (Uexküll, [1934]1982, p. 25). ${ }^{1}$ Não nos ocuparemos da noção de Umwelt em detalhe. Ela nos interessa na medida em que é no interior de um Umwelt que um objeto tem significado. Segundo Uexküll, quando um organismo apreende um estímulo sensorial do mundo, não ocorre somente um processo mecânico de causa e efeito. Um estímulo apreendido representa um sinal ou signo que significa um objeto: cada experiência tem um aspecto significativo particular de relação entre organismo e mundo. Assim, para Uexküll, enquanto o fisiologista tenta explicar o aspecto mecânico do comportamento isolado do ambiente, o biólogo procura compreender a relação de significação entre organismo e objeto em que ambos estão concretamente situados no ambiente. Segundo Uexküll, é o significado que ocupa o lugar do objeto de investigação do biólogo. Por significado, contudo, não se entende conteúdo objetivo de pensamento. $\mathrm{O}$ significado é parte do processo de relação entre organismo e mundo.

Como premissa epistemológica, a teoria de Uexküll segue uma perspectiva de observador-dependente: a interpretação humana de um comportamento já é interpretação de interpretação. Mas, o problema é exatamente como um intérprete humano pode compreender a interpretação de um organismo sem distorcer ou corromper seu significado original. Aqui, certamente, temos um problema de tradução radical. De uma certa perspectiva filosófica, a teoria de Uexküll consiste em uma teoria da tradução dos diferentes Umwelten.

Não é tarefa trivial aproximar duas perspectivas que estão em campos teóricos distintos em relação ao problema da tradução: do lado de Quine, o problema filosófico da tradução; do lado de Uexküll, o problema da tradução humana do comportamento animal não humano. O que nos propomos a mostrar, no entanto, é que, além do significado filosófico da tradução radical de Quine, ela pode ser muito bem ilustrada segundo a teoria do significado de Uexkül. Como teoria empírica, os conceitos e resultados tirados da teoria de Uexküll estariam em continuidade com a perspectiva filosófica da tradução radical de Quine.

1 Umwelt corresponde em português a ambiente, mundo ambiente ou, com menos propriedade, meio ambiente. No sentido de Uexküll, Umwelt significa alguma coisa que depende de um ser vivo particular e resulta de uma seleção de elementos do ambiente por ele realizada no mundo (Uexküll, [1934] 1982, p. 24 - nota do tradutor). 


\section{Os princípios da tradução radical}

Para muitos filósofos, a ideia de indeterminação da tradução soa absurda e comprometeria a própria concepção da arquitetura analítica na filosofia contemporânea. Nas práticas comuns de comunicação, ninguém parece duvidar que se alguém tem uma ideia, ela pode ser transmitida e compreendida por outras pessoas. Assim seria o caso da tradução entre linguagens diferentes. Logo, afirmar a indeterminação do significado seria condenar a possibilidade da tradução. Este é o estado da arte na proposta de tradução radical de Quine.

Inicialmente, é preciso destacar que a tradução radical não é ela mesma uma teoria. Trata-se de uma experiência de pensamento por meio da qual Quine pretende mostrar a tese da indeterminação da tradução. Ele propõe que se imagine uma situação na qual um linguista deve desenvolver um manual de tradução de uma tribo cuja língua é completamente desconhecida, sem qualquer proximidade linguística com qualquer outra língua existente e da qual não se pode contar com a ajuda de intérpretes.

Para a tradução, o linguista tem à sua disposição somente dados do comportamento observado dos nativos: estimulações empíricas e resposta dos nativos a tais estimulações. A tentativa de tradução começa com a análise de unidades sentenciais associadas a certas condições de estimulação dos próprios nativos. O linguista deve, portanto, recuperar o significado das unidades sentenciais utilizando dados objetivos como a observação daquilo que causa algum efeito nos nativos e em seu comportamento vocal ou não vocal. ${ }^{2}$ Os dados da observação, a princípio, indicam significados objetivamente empíricos e, em seguida, tornam-se propostas para tradução de todas as sentenças da língua nativa.

Observando a conexão entre a enunciação e a situação, o linguista percebe que quando um coelho passa saltitante o nativo diz 'Gavagai!'. O linguista imediatamente anota a primeira proposta de tradução: 'Coelho!' ou 'Eis um coelho!' Essa tradução, no entanto, é preliminar e deve ser submetida a testes posteriores em diferentes situações estimulativas (Quine, 1960, p. 28). Em cada situação, o linguista enuncia 'Gavagai?' e, a partir da resposta do nativo, ele começa a apurar se a enunciação significa consentimento ou dissentimento: o linguista percebe que, ao consentir, o nativo profere 'Evet' e, ao dissentir 'Yok'. O linguísta compreende que as enunciações 'Evet' e 'Yok', respectivamente, significam 'sim’e ‘não' (Quine, 1960, pp. 28-29).

2 Embora as ferramentas principais para a tradução radical sejam a enunciação do nativo e a situação em que a sentença foi enunciada, Quine aceita que detalhes do comportamento dos nativos (movimentos oculares, expressões faciais, etc.) também podem ser elementos relevantes no processo de tradução radical. 
A primeira dificuldade que Quine (1960, p. 30) aponta é que, ainda que em todas as situações em que se tem a presença de um coelho o nativo enuncia 'Gavagai', a enunciação é incitada pela estimulação e não pelo coelho. Inclusive na ausência de um coelho, é possível que a estimulação permaneça a mesma e, nesse caso, ela é apenas uma simulação. Assim, pode haver uma classe de estimulações anteriores ou posteriores que levem o nativo a perceber uma 'presença de coelho' ainda que o objeto coelho não esteja em seu campo de visão:

The difficulty would thus arise that far from hoping to match the irradiation patterns favorable to 'Gavagai' with those favorable to 'Rabbit', we could not even say unequivocally of an irradiation pattern of itself and without regard to those just before and after, that it is favorable to 'Rabbit' or that it is not. Better, therefore, to take as the relevant stimulations not momentary irradiation patterns, but evolving irradiation patterns of all durations up to some convenient limit or modulus. (Quine, 1960, pp. 30-31)

Assim, temos o significado estimulativo de 'Gavagai' que vai além da presença de um coelho e, portanto, inclui informações colaterais, ou seja, informações que todos os nativos têm e que os levam a consentir a 'Gavagai?' mesmo na ausência de um coelho. É o caso, por exemplo, da existência de uma mosca-de-coelho local da qual todos os nativos têm a informação de que ela sempre acompanha um coelho. O linguista, porém, não tem essa informação. Na presença da mosca, os nativos sempre consentem para 'Gavagai?' mesmo que o coelho não esteja em seu campo de visão. A mosca pertence ao significado estimulativo de 'Gavagai' sem pertencer ao significado estimulativo de 'coelho'. Uma mesma estimulação levaria o nativo a consentir para 'Gavagai?' e o linguista a dissentir para 'Coelho?'.

A informação colateral interfere diretamente na tradução feita por meio de significados estimulativos que é justamente a ferramenta da qual dispõe o linguista. Aqui dois conceitos fundamentais se convergem:

a) Significado estimulativo: que é a disposição para consentir ou dissentir causada; neste caso, pela presença ou ausência de um coelho e seguida pela indagação do linguista 'Gavagai?'”

b) Informações colaterais: que são as informações amplamente difundidas entre os nativos da tribo que os levam a perceber uma situação para consentir a 'Gavagai?' na ausência de um coelho no contexto. 
A presença de informações colaterais leva à dificuldade de desenvolver a tradução pela observação. O que Quine desenvolve, posteriormente, e que nos interessa presentemente, é que, por um lado, o único critério confiável que dispomos para a tradução é a evidência empírica; e, por outro lado, estamos limitados a um esquema conceitual que leva à indeterminação da tradução. Aqui, no entanto, precisamos distinguir entre dois tipos de indeterminação:

a) Indeterminação de referência: algumas sentenças podem ser traduzidas em mais de um modo e as várias versões diferem sobre a referência. Neste caso, temos a 'inescrutabilidade da referência'.

b) O segundo tipo de indeterminação é eventualmente referido por Quine como 'holfrástica' e significa que há mais de um método correto de traduzir sentenças.

Ambos os tipos de indeterminação são análogos. No primeiro tipo, trata-se de tradução de palavras; e, no segundo, de sentenças. É também no primeiro caso que se pode dizer se trata de uma tese atenuada de indeterminação. Segundo o exemplo de Quine, 'gavagai' pode ser traduzido como 'coelho', 'parte de coelho', 'coelhidade' etc. E mesmo se consideradas possíveis identidades, não se pode verificar a intersubjetividade de sinônimos entre 'gavagai' e 'coelho'. Talvez o nativo use 'gavagai' em situações semelhantes ao linguísta quando este usa a palavra 'coelho'. Mas, isso ainda poderia significar alguma coisa diferente e as tentativas de se traçarem paralelos entre os usos de 'gavagai' e 'coelho' se estenderiam indefinidamente. Quine mostra que a tradução de 'gavagai' encontra como as dificuldades de uma visão denotacionista do significado: uma certa visão da linguagem segundo a qual as palavras denominam objeto e cada uma tem um significado próprio.

Como consequência, não se pode pretender uma tradução radical, na medida em que não se pode estar certo da compreensão exata de qualquer enunciação linguística. Uma tal dificuldade da tradução radical antecipa aqui um paralelo com a teoria do significado de Uexküll: nossa interpretação humana de um comportamento já é interpretação de interpretação e, portanto, a tradução radical representaria um limite nosso de compreender as diferentes e desconhecidas formas não humanas de significar a relação com o mundo. Segundo Uexküll, no entanto, mundos desconhecidos se abrem a nós quando eles representam percepções próprias do mundo e um novo mundo de significados emerge. ${ }^{4}$ environment and contains all the features accessible to the subject. As soon as we enter into one such bubble, the previous surroundings of the subject are completely reconfigured. Many qualities of the colorful meadow 
Como 'gavagai' pode ser melhor compreendido não como uma palavra que significa 'coelho', mas como um enunciado 'partes de coelho', 'coelhidade', etc., não se consegue reduzir o significado a um conjunto de eventos sensoriais, ou a um tipo de experiência, e que vários significados são possíveis e dependem de um contexto bem mais amplo. Tal contexto inclui informações colaterais e experiências recalcitrantes e, finalmente, envolve todo um esquema conceitual. É assim que Quine chega à tese do 'holismo semântico': não é possível falar de significado de um termo ou enunciado sem apoiar-se em todo um esquema conceitual.

Mas um problema se apresenta com o esquema conceitual: como sustentar a comunicação ou uma tradução sem reduzir um esquema conceitual a outro? Para Quine, o que esse problema nos leva é, finalmente, a uma concepção pragmática da verdade. O critério de verdade é aquilo que um sujeito ou uma teoria inclui no domínio de seu discurso para que as sentenças sejam verdadeiras. É necessário que haja uma decisão pragmática sobre qual tradução ou qual discurso serve melhor à comunicação sem que isso gere um compromisso absoluto. Toda sentença ou tradução deve estar sempre disponível para serem revisadas, abandonadas ou substituídas. É necessário escolher uma tradução ou discurso que atenda minimamente aos diferentes esquemas conceituais.

Na medida em que a teoria do significado de Uexküll não visa estabelecer uma teoria da mente, parece inegável ter ela a mesma dificuldade de evitar a redução de um esquema conceitual a outro. ${ }^{5}$ No sentido da teoria de Uexküll, contudo, as formas desconhecidas de significar a relação com o mundo e emergir um novo mundo de significado não se derivam de um esquema conceitual nosso (humano). Como formas de significar, as formas desconhecidas de vida têm linguagem, conceitos e regras próprias que estão além do nosso esquema conceitual humano. Não é por acaso que Uexküll afirma ser seu método de investigação um passeio por mundos desconhecidos. O problema é, no entanto, como um tradutor humano pode compreender um mundo desconhecido de experiências sem distorcer ou corromper seu significado original.

vanish completely, others lose their coherence with one another, and new connections are created. A new world arises in each bubble" (Uexküll, [1934] 2010, p. 43).

5 Como parte das ciências cognitivas, 'teoria da mente' (ou 'psicologia do senso comum') consiste na investigação das estratégias de explicação e atribuição de estados mentais a nós mesmos e a outros que possam predizer ações e comportamentos. 


\section{Teoria do significado de Uexküll: um caso de tradução radical}

Thure von Uexkül, filho mais velho de Jakob, destaca três sentidos de tradução:

(1) traduções de signos em outros signos de uma mesma língua [ou] "tradução intralingüística ou paráfrase"; (2) traduções entre línguas diferentes, [ou] "tradução no sentido estrito da palavra"; e (3) traduções para um sistema sígnico não-verbal [ou] "tradução intersemiótica ou transmutação" (2004, p. 17).

Se considerada a tradução de 'gavagai', é evidente ser o caso de tradução no sentido estrito. Mas, se considerada a interpretação do comportamento animal não humano, o caso que se apresenta é a 'tradução intersemiótica ou transmutação'. Podemos, então, reelaborar o problema da tradução radical segundo um exercício de imaginação: se imaginamos uma forma de vida desconhecida, seguramente, imaginamos também um esquema conceitual diferente com conceitos, regras e linguagem diferentes. Como o linguísta que é desafiado a traduzir uma língua desconhecida, sem qualquer proximidade linguística com qualquer outra língua existente e da qual ele não pode contar com intérpretes, também nós somos tentados a traduzir formas de vida desconhecidos a nós e completamente alheias ao nosso esquema conceitual humano. De fato, segundo Thure von Uexküll, nossa tradução humana de formas de vidas desconhecidas é uma interpretação de interpretação. Assim, em comparação aos termos de Quine, tais formas de vida têm conceitos, regras e linguagem próprios e, portanto, têm diferentes esquemas conceituais. Nesse caso, se nem a redução de esquemas conceituais indica uma alternativa para preencher a lacuna entre diferentes formas interpretativas, estamos diante do limite extremo de um caso de tradução radical. Como 'a tradução de um poema em melodia' (Uexküll, 2004, p. 17), assim também se mostra a tradução humana do comportamento animal não humano como uma transmutação da significação. A questão é, então, por que a teoria do significado de Uexküll é um caso de tradução radical?

A teoria do significado é a segunda parte da teoria de Umwelt de Uexküll. Como conceito-operador, o termo Umwelt se aplica à caracterização de diferentes e desconhecidas formas de significar e agir no mundo. Para Uexküll, cada organismo vivo tem um Umwelt particular que representa uma unidade entre mundo de percepção (sistema receptor) e mundo de ação (sistema efetuador); logo, diferentes organismos têm diferentes Umwelten. No mundo de percepção, está tudo o que um organismo percebe em seu entorno, por meio de seus órgãos receptores, e induz nele a apreensão significativa de determinadas características sensíveis do mundo. No mundo de ação, o organismo age sobre o mundo por meios dos órgãos efetuadores. As relações de significação entre organismo 
e objeto obedecem sempre à unidade circular e dinâmica entre mundo de percepção e mundo de ação.

Na ilustração a seguir, temos a representação do Umwelt segundo o esquema do 'ciclo de função':

\section{FIGURA 1 - Ciclo de Função}

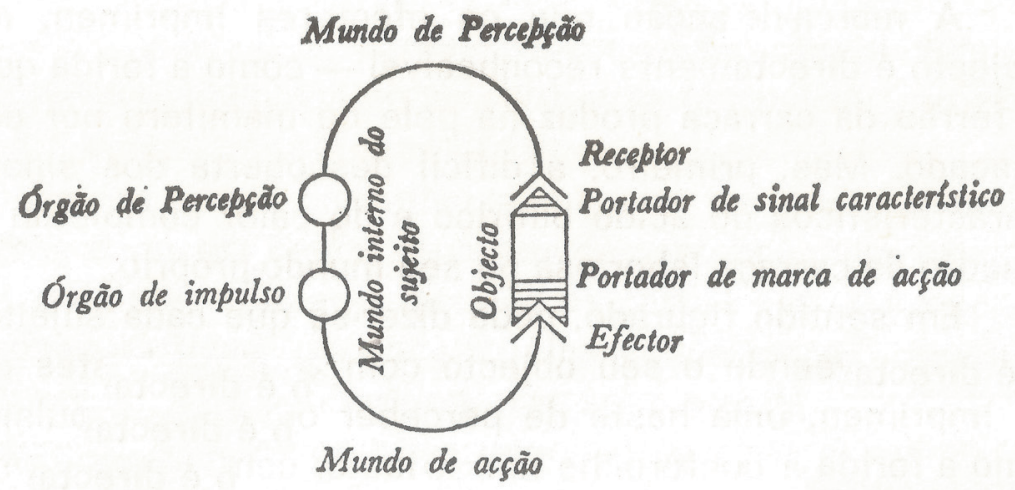

Fonte: Ciclo de função: Uexküll, [1934] 1982, p. 36.

No esquema do ciclo de função, pode-se notar a clara distinção entre mundo interno e a estrutura do Umwelt segundo a unidade entre mundo de percepção e mundo de ação.

Thure von Uexküll (2004) destaca o sentido particular que a noção de objeto ganha na teoria do pai. Segundo ele (Uexküll, 2004, p. 2), 'objeto' antecipa a concepção de sistema aberto. Assim, nada se pode afirmar definitivamente sobre o significado dos objetos, na medida em que eles não podem ser isolados da relação com um organismo; logo, o que se pode observar é tão somente a relação entre organismo e objeto. O esquema do ciclo de função mostra que a teoria de Umwelt se afasta de uma concepção realista do significado de objeto: i.e, tradicionalmente, um objeto se define por localização simples (no espaço e tempo) e relação entre substância e qualidades. ${ }^{6}$ Segundo o esquema do ciclo de função de Uexküll, alternativamente, um objeto é, de fato, um objeto

6 Sobre a crítica ao realismo das noções de localização simples e relação substância e qualidade, ver Whitehead (1948, p. 53): "There is another presupposition of thought which must be put beside the theory of simple location. I mean the two correlative categories of Substance and Quality [...] their usual genius, they at once constructed a theory which was adequate for their immediate purposes. Of course, substance and quality, as well as simple location, are the most natural ideas for the human mind". 
estrutural e ele só tem significado no interior de um Umwelt como um campo de relações - vide esquema do ciclo de função. ${ }^{7}$

De um ponto de vista epistemológico, portanto, o esquema do ciclo de função relativiza o significado de objeto enquanto mostra que função tem a interpretação humana em dois possíveis sentidos (Uexküll, 2004; Sharov, 1998):

1. Não se aceitam modelos determinísticos ou probabilísticos, ou seja, um modelo observador-independente - as interpretações humanas são interpretações de interpretações ou 'meta-interpretações' (Uexküll, 2004, p. 6).

2. A defesa de uma concepção de determinismo subjetivo (como expectativa ou meta de um organismo) - sistemas ou seres vivos são intérpretes autônomos do mundo.

O esquema do ciclo de função é instrumental. ${ }^{8}$ Ele estabelece os limites de caracterização das diferentes estruturas de apreensão significativa do mundo e, contudo, ele não induz um modelo realista de tradução. O que o esquema do ciclo de função expõe é justamente a relação estrutural de significação entre organismo e objeto, e, no entanto, ele não representa um princípio de tradução da realidade: primeiro, porque a realidade é uma apreensão significativa no interior do Umwelt; e, segundo, consequentemente, a significação da realidade depende de determinismo subjetivo. $\mathrm{O}$ ciclo de função nos habilita à compreensão da estrutura do Umwelt do organismo em que nós, observadores humanos, somos intérpretes de interpretações de mundo. Devemos ter cuidado, contudo, e não ceder à tentação de reduzir as interpretações de mundo às nossas interpretações humanas e esquemas conceituais. Em termos epistemológicos, a teoria da significação de Uexküll nos impõe o limite do modelo observador-dependente: os organismos são intérpretes de $1^{\text {a }}$ ordem do mundo e, com efeito, não se apreende a significação de um objeto como uma realidade objetiva. ${ }^{9}$ Aliás, se, como descrito no esquema do ciclo de função, o Umwelt tem uma característica comum de unidade de significação entre diferentes organismos, a própria significação do objeto pode variar e é difícil ver o significado como conteúdo objetivo, discreto e tendo localização simples em uma relação particular.

7 "Observation teaches us that each animal moves within its habitat and confronts a number of objects, with which it has a narrower or wider relationship. Because of this state of affairs, each experimental biologist seems to have the task of confronting various animals with the same object, in orcjer to investigate the relationships between the animal and the object" (Uexküll, [1934] 1982, p. 27).

8 Aliás, vale assinalar aqui, como parte da sua concepção do pragmatismo, William James ([1907] 2000, p. 28) afirma que nossas teorias são 'instrumentos' e não respostas a 'enigmas' do mundo.

9 "Because no animal ever plays the role of an observer, one may assert that they never enter into relationships with neutral objects" (Uexküll, [1934] 1982, p. 27). 
Assim como o linguista que tem à disposição somente dados do comportamento observado dos nativos, de igual modo, o biólogo somente dispõe de dados do comportamento observado dos organismos. No entanto, como o significado do objeto varia segundo a relação com um organismo particular, a tradução do significado de um objeto tem como limite a variedade de comportamentos observados. Em função do limite de observação, o resultado é a impossibilidade de uma tradução radical e a consequente indeterminação do significado de um objeto entre diferentes tipos de comportamento. ${ }^{10}$

Como ilustração da impossibilidade de tradução radical na teoria do significado de Uexküll, temos o seguinte exemplo: o talo de flor e sua apreensão significativa por diferentes organismos (como uma garota, uma formiga, uma larva ou uma vaca) - os casos de apreensão significativa do talo poderiam ser multiplicados indefinitivamente. Nada muda objetivamente no talo de flor e, no entanto, ele tem diferentes significados segundo o Umwelt em questão: a garota toma o talo como um enfeite de cabelo; a formiga vê nele um caminho para alcançar o topo; perfurando o talo, a larva vê um abrigo; e, finalmente, para a vaca, o talo significa alimento: "Os mesmos elementos que no pedúnculo [talo] da flor estão submetidos a um acertado plano-de-construção são separados uns dos outros, levados para os quatro mundos-próprios e perfeitamente ajustados, com igual certeza, a outros planos de construção" (Uexküll, [1934] 1982, p. 145).

Assim como, por exemplo, o significado ‘caminho' não existe no Umwelt da garota, o 'enfeite' nada significa à formiga. Então, qual é o significado de 'talo'? Ele pode ser isolado e identificado como um conteúdo objetivo, discreto e tendo localização simples em uma relação particular? Embora o talo seja significativamente relevante no interior de diferentes Umwelten, o significado mesmo varia. Como elemento variante, só se pode ver o significado como parte de uma relação ou processo que une organismo e objeto. Assim, como destacado por Maturana ([1959] 1968), o observador é participante da observação e, com efeito, a noção de objetividade deve ser relativizada. Aqui, comparativamente, considerando-se o significado do talo de flor, o observador está intrinsecamente imerso como interpretante das relações ou processos de significação entre diferentes organismos e o objeto.

10 É importante destacar aqui a noção de 'interpretação radical' de Donald Davidson (1973). Davidson substitui o termo 'tradução' de Quine por 'interpretação'. Segundo ele, não se compreende o significado dos enunciados de um falante sem conhecimento das suas crenças. Da relação entre significado e crença, podemos usar nossas crenças como guia e compreender o significado dos enunciados do falante. A ideia de 'interpretação radical' de Davidson não é, contudo, um guia de tradução. É uma teoria sobre a relação entre significado e crença. Para Davidson, a interpretação radical implica um intérprete ideal que teria um papel heurístico. Se comparado com a atividade do biólogo, segundo Uexküll, ela poderia desempenhar tal papel heurístico de interpretação das diferentes significações de mundo estranhas a nós seres humanos. 
Muito dificilmente se poderia apreender o significado como conteúdo objetivo, discreto e tendo localização simples em uma relação particular. Tais propriedades representariam os aspectos de uma visão denotacionista do significado. Mas, como assinala Gilbert Ryle, seguindo um dos princípios das Investigações de Wittgenstein (PI, 6; 10; 43), muito mais do que a denotação, a significação de uma palavra está associada ao seu uso: "não pergunta pelo significado, pergunte pela utilização" (Ryle, [1957] 1975, p. 70). Se comparado ao princípio de significação como uso, o significado do talo de flor é a função para cuja execução ele é usado. Logo, identificar o significado do talo é identificar como ele é usado por diferentes organismos.

Aliás, anterior à teoria de Umwelt, em "Theoretical Biology" (1926, p. XV), diferentemente da apreensão da realidade objetiva de um objeto na física, na biologia, Uexküll afirma que a realidade é apreensão subjetiva: nunca se apreende a realidade independentemente de um organismo. Uexküll nega que a realidade tenha o significado redutível a um único ponto de vista e, consequentemente, ele sugere uma visão pluralista de mundo. Não há uma única e objetiva de apreensão do significado da realidade e cada organismo tem uma experiência de mundo só sua. O problema aqui é que os significados das experiências de mundo não são redutíveis entre si. Afirmar que o significado 'talo' é 'caminho' no Umwelt da formiga não é senão uma interpretação nossa de uma experiência de mundo desconhecida a nós. Tal significação é uma interpretação da nossa observação da relação entre a formiga e o talo. Mas, um fato parece bem claro: embora não tenhamos acesso ao significado das experiências de mundo desconhecidas a nós, não se apreende o significado senão como parte de uma relação ou processo entre organismo e mundo.

Tudo quanto cai na esfera de um mundo-próprio [Umwelt], ou desaparece totalmente ou é adaptado e transformado até se converter num objeto com significado útil. [...] Dentro dos vários mundos-próprios, os objectos significantes são tão diferentes pelo seu conteúdo quanto se assemelham pela natureza de sua estrutura (Uexküll, [1934] 1982, p. 146).

O que a teoria do significado de Uexküll nos mostra é que um objeto não tem como significado um conteúdo objetivo, discreto e com localização simples: mas, ao contrário, o significado de um objeto é apreendido no interior de um Umwelt, é parte de um processo e não tem localização simples. Há, portanto, uma indeterminação do significado do objeto e, consequentemente, a irredutibilidade entre os diferentes significados no interior de diferentes Umwelten. Mas, se, por exemplo, podemos traduzir a sentença 'talo é x' em mais de um modo, as várias versões mostrariam também uma variação sobre 
a referência. Logo, no caso da tradução de 'talo, teríamos a 'inescrutabilidade da referência'. De novo, não se pode apreender o significado como conteúdo proposicional objetivo, discreto e tendo localização simples. Se considerado o significado de 'talo, ele só se apreende como parte de uma relação ou processo entre organismo e objeto. Assim, o significado não corresponde a um tipo de representação mental ou a uma entidade platônica ideal. Como sugere a tese da indeterminação de Quine, na teoria de Uexküll, comparativamente, o significado de um objeto não tem nenhuma determinação (mentalista ou realista) fora das relações concretas com um organismo.

Como, então, compreender o significado de um objeto no interior de um Umwelt radicalmente diferente do nosso? O que parece é que essa compreensão nos leva justamente ao processo de tradução radical. No entanto, enquanto a tradução radical de Quine lida com a dificuldade entre diferentes esquemas conceituais, na teoria do significado de Uexküll, a tradução de significado de um objeto entre diferentes Umwelten tem como limite o esquema dos diferentes planos de construção.

Além do ciclo de função, é igualmente importante destacar que, desde a fase embrionária do organismo, a significação de um objeto também depende de um determinismo morfogenético que atua sobre órgãos, anatomia e capacidades sensório-motoras. Aliás, uma premissa importante da teoria de Uexküll é que os organismos se constroem por si mesmos segundo um plano de construção e este não está situado fora do organismo. Segundo Uexküll, somente máquinas têm planos exteriores a elas mesmas. O plano de construção responde a questões como, por exemplo, como é que um organismo é o que é. ${ }^{11} \mathrm{O}$ plano de construção molda o Umwelt do organismo. Assim, por exemplo, no Umwelt da abelha, encontram-se coisas de abelhas; na larva, coisas de larva; na formiga, coisas de formiga; no sapo, coisas de sapo e assim indefinidamente. Tomando a expressão emprestada de Quine, parece correto afirmar que um plano de construção supõe um esquema conceitual que tem estrutura e lógica próprias. O desafio que impõe a teoria de Uexküll é que a cada aparição de um Umwelt um mundo novo de significado se mostra e ele nos impõe um enigma a ser decifrado.

O linguista e o nativo têm em comum uma mesma estrutura: ambos obedecem ao plano de construção dos seres humanos. Considerando o caso de compreender o significado do talo de flor, contudo, o primeiro desafio que se nos impõe é compreender os distintos planos de construção entre diferentes organismos vivos. A compreensão do que significa o talo de flor passa por 
um processo semelhante ao que é necessário para a compreensão do que é o 'Gavagai!'. Seria o significado de 'talo' o gavagai do biólogo?

Se considerada a presença de informações colaterais segundo Quine, a dificuldade consiste em desenvolver a tradução pela observação. Assim, por informações colaterais, podemos associar o conhecimento prévio da estrutura e modo de vida do organismo. Para quem tem um conhecimento, por exemplo, das necessidades biológicas de uma larva, é fácil compreender a relação entre esse organismo e o talo de um modo diferente de quem não tem. O significado estimulativo é, portanto, desencadeado pela presença do objeto que, somado à disposição biológica do organismo, torna-se um objeto significativo. Se, no caso do nativo, a presença de um coelho seguida da pergunta 'Gavagai?' provoca uma resposta positiva ou negativa, no caso de diferentes organismos, a percepção do talo depende de um determinado plano de construção e induz diferentes significados. A compreensão do significado de um objeto no interior de um Umwelt parece encontrar as mesmas dificuldades da tradução radical.

Uma superação de tais dificuldades talvez seja adotar um critério pragmático para a tradução do significado de um objeto entre diferentes Umwelten. Entre os quatro tipos diferentes de Umwelten, no exemplo do talo de flor, o significado resulta do efeito de uma ação particular sobre ele. Da observação do comportamento aliada ao conhecimento da estrutura do Umwelt, pode-se afirmar que, da ação do organismo sobre o objeto, o significado emerge como efeito. Assim, segundo um critério pragmático, o ciclo de função oferece um esquema de apreensão do significado de um objeto entre diferentes Umwelten. No entanto, como adverte Quine sobre a tradução, uma tal apreensão do significado não é absoluta e deve estar aberta a revisões a partir de novas informações colaterais. Podemos sempre revisar nossas apreensões do significado no interior de diferentes Umwelten, na medida em que o esquema do ciclo de função é instrumental e não nos impõe o compromisso com um modelo realista de representação da realidade.

Aliás, segundo Mark Johnson (1990, p. XXI), uma forma tradicional de teoria objetivista do significado afirma que as relações entre mente, linguagem e mundo assumem a realidade como fixa, determinada e independente da mente. No sentido filosófico amplo, é uma teoria que implica uma forma de realismo metafísico: os objetos que o mundo contém com suas propriedades e relações existem independentemente de concepção individual. Assim, o significado é uma relação abstrata entre certos tipos de representação (palavras ou representações mentais) e a realidade do mundo independente da mente. De um ponto de vista epistemológico, a teoria objetivista do significado apoia um ponto de vista do 'Olho de Deus' (Johnson, 1990, p. XXIII): uma perspectiva que transcende as 
limitações das experiências particulares de mundo e, com efeito, o significado é uma relação entre representações e estados de coisas no mundo independente de apreensão individual.

É claro que uma perspectiva antirrealista nega uma tal visão objetivista de significado e mundo como realidades independentes da mente. Se não exatamente como uma perspectiva antirrealista, e segundo a tese da indeterminação de Quine, a teoria de Uexküll induz a negação de uma teoria objetivista do significado e do realismo que ela implica: assim como não se apreende o mundo sob a visão do Olho de Deus, de igual modo, o significado de um objeto não é nunca uma realidade neutra apreendida independentemente da relação com um organismo (Uexküll, [1934] 1982, p. 27) - se se pode atribuir ao significado uma realidade, certamente, ele não corresponde a uma forma abstrata, isolada e fora da relação com um organismo. Assim, contrariamente à visão do Olho de Deus, a teoria do Umwelt de Uexküll situa o significado segundo um ponto de vista pluralista de relação entre organismo e mundo.

De novo, lembramos aqui, o esquema do ciclo de função não representa um princípio de tradução. O que ele nos permite compreender é a estrutura de apreensão significativa de um objeto no interior de diferentes Umwelten. O ciclo de função mostra que nossa interpretação humana de mundos desconhecidos a nós é a interpretação de uma interpretação e que, portanto, não podemos esperar que o significado de um objeto seja uma propriedade nossa. Como ilustração da estrutura dos diferentes Umwelten, o ciclo de função expõe o significado empírico da tradução radical de Quine assim como mostra o alcance filosófico da teoria do significado de Uexküll.

\section{Considerações finais}

É importante destacar que este artigo é resultado de uma dissertação de mestrado e de uma pesquisa sobre o trabalho de Uexküll desenvolvida por nós no Programa de Pós-Graduação em Filosofia da Ufes. Nosso objetivo consiste em explorar o potencial filosófico da teoria do significado de Uexküll em consonância com a importante contribuição de Quine ao estudo da significação e sua ideia de indeterminação da tradução. Entre Quine e Uexküll, com efeito, a questão nos parece ser: como se pode compreender a noção de significado? Do lado de Quine, a tradução radical mostra que, entre uma comunidade humana em que os indivíduos têm diferentes esquemas conceituais, a resposta é que o significado é indeterminável. Do lado de Uexküll, a teoria do significado mostra que, quando lidamos não apenas com esquemas conceituais diferentes, mas, também com planos de construção diversos e incontáveis, as dificuldades de compreensão do significado avançam a um nível maior de indeterminação. 
Uma alternativa possível talvez seja adotar uma atitude pragmática diante do desafio da apreensão do significado de objetos entre diferentes esquemas conceituais e Umwelten: que nossas interpretações humanas de mundo desconhecidos a nós são interpretações de interpretações e que elas estão abertas a revisões. Do ponto de vista de Uexküll, assim nos parece, o significado do talo de flor segue o destino da tradução de 'gavagai'.

\section{Referências}

DAVIDSON, D. "Radical Interpretation”. Dialectica, Vol. 27, pp. 314-328, 1973. JAMES, W. "Pragmatism and other writings". New York: Penguin Books, 2000. JOHNSON, M. "The Body in the Mind". Chicago: The University of Chicago Press, 1990. MATURANA, H. et al. "What the frog's eye tells to the frog's brain". Reprinted from: The Mind: Biological Approaches to its Functions. Editors: William C. Corning, Martin Balaban, 1968. pp. 233-258.

NAGEL, T. "What is it like to be a bat?" The Philosophical Review, Vol. 82, pp. 435450, 1974.

QUINE, W. O. “De um ponto de vista lógico". São Paulo: Unesp, 2011. . "Word and Object". Cambridge: The MIT Press, 1960.

RYLE, G. "Teoria da Significação". Tradução de Oswaldo Porchat de Assis Pereira da Silva. São Paulo: Abril Cultural, 1975.

SHAROV, A. "Umwelt Theory and Pragmatism". In: Semiotica. Toronto: De Gruyter Mouton, 2001. Vol. 134, pp. 211-228.

UEXÜLL, J. "A Stroll thoough the Worlds of Animals and Men”. In: Instinctive Behavior. Claire H. Schiller (Ed.). New York: International University Press, 1957. . "Dos animais e dos homens". Tradução de Alberto Candeias e Aníbal Garcia

Pereira. Lisboa: Livros do Brasil, 1982. . "The Theory of Meaning”. Semiotica, Copenhagen. Vol. 42-1, pp. 25-82, 1982. . "Theoretical Biology". New York: Harcourt, Brace \& Company, 1926.

UEXÜLL, T. "A teoria da Umwelt de Jakob von Uexüll”. Revista Galáxia, São Paulo, Nr. 7, pp. 19-48, abril 2004.

WHITEHEAD, A. N. "Science and the Modern World". New York: Pelican Mentor Books, 1948.

WITTGENSTEIN, L. "Philosophical Investigations". Translated by G. E. M. Anscombe. Oxford (UK): Basil Blackwel, 1958. 